\title{
(4) PENGUKURAN GROUNDING SIIP PANEL DISTRIBUSI INSTALASI REKAM MEDIS RSUP DR. MOHAMMAD HOESIN PALEMBANG
}

\author{
Dian Eka Putra ${ }^{1}$, Jaka Udi ${ }^{2}$ \\ Program Studi Teknik Elektro Fakultas Teknik Universitas Palembang \\ e-mail : dianeka.putra@ymail.com
}

\begin{abstract}
ABSTRAKPenggunaan Energi Listrik berbanding lurus dengan keandalan instalasi listrik yang digunakan pada gedung instalasi rekam medis RSUP DR. Mohammad Hoesin Palembang, didalam aktivitasnya menggunakan peralatan canggih (complicated). Salah satunya pada instalasi listrik yaitu pada instalasi grounding atau pentanahan. Nilai resitansi atau tahanan pentanahan menurut Persyratan Umum Instalasi Listrik (PUIL) 2000 tidak melebihi $5 \Omega$, sehingga Berdasarkan perhitungan dengan variabel-variabel didapat nilai resistansi yaitu $0,67 \Omega$, sehingga perlunya ada perbandingan nilai resitansi dari hasil perhitungan dengan nilai resitansi hasil pengukuran langsung pada sistem grounding tahanan pentanahan pada waktu pagi dan sore hari di panel listrik instalasi rekam medis RSUP Dr. Mohammad Hoesin Palembang. Dari hasil pengukuran langsung pada pagi hari antara pukul 07.30 sampai 10.30 Wib didapatkan nilai tahanan resistansi dengan rata-rata $0.11 \Omega$, Berdasarkan pengukuran resistansi tahanan pentanahan pada waktu sore hari pada pukul 15.00 sampai 17.00 Wib didapatkan nilai tahanan resistansi dengan rata-rata $0.07 \Omega$.
\end{abstract}

Kata kunci : Grounding, Resistansi, Cuaca, Rekam Medis RSUP Dr. Moh Husien.

\begin{abstract}
The use of electrical energy is directly proportional to the reliability of electrical installations used in the building of General Hospital DR. Mohammad Hoesin Palembang, in his activities using sophisticated (complicated) equipment. One of them is in the electrical installation, namely the installation of grounding or earthing. Grounding resistance value according to General Electrical Installation (PUIL) 2000 does not exceed $5 \Omega$, so that based on the calculation with the variables, the resistance value is $0.67 \Omega$, so there is a need for a comparison of the value of the resitance from the calculation with the value of the resitance directly to grounding, grounding system in the morning and evening in the electrical panel of General Hospital medical record installation Dr. Mohammad Hoesin Palembang. From the results of direct measurements in the morning between 7:30 a.m. and 10:30 p.m, resistance resistance values were obtained with an average of $0.11 \Omega$. Based on measurements of ground resistance resistance in the afternoon at 3:00 p.m. to 5:00 p.m., resistance resistance values were obtained with an average of $0.07 \Omega$.
\end{abstract}

Keywords: Grounding, Resistance, Weather, Medical Records General Hospital Dr. Mohammad Hoesin.

\section{PENDAHULUAN}

Nilai resistansi pertanahan harus sekecil-kecilnya agar bila terjadi kebocoran arus kebagian logam peralatan listrik (yang seharusnya tidak boleh bertegangan), tidak akan membahayakan orang yang tidak sengaja menyentuh bagian logam peralatan itu. [1]

Grounding dengan keandalan yang tinggi dan sesuai standar akan meningkatkan kinerja peralatan listrik yang digunakan. Kita ketahui bahwa dalam sistem tenaga listrik tidak mungkin dapat menyediakan tenaga listrik yang secara mutlak tanpa gangguan. [2] 
Komponen Elektronika yang sedang bekerja menyebabkan timbulnya radiasi elektromagnetik, seperti imbas elektromagnetik, ggl indukasi dan arus induksi yang dilepaskan keluar. Besaran-besaran ini menyebabkan efek radiasi pada komponen elektronika yang lain. Radiasi ini bersifat merusak. Jika hal ini dibiarkan maka akan menimbulkan kerusakan yang mengakibatkan pemborosan energi listrik maupun munculnya bahaya kebakaran dan resiko tersengat listrik. [3].

\section{TINJAUAN PUSTAKA}

\section{Sistem Pentanahan}

Salah satu pengaman yang paling baik terhadap peralatan listrik dari gangguan arus lebih ataupun hubungan singkat yaitu, dengan cara pentanahan. Cara ini juga dapat melindungi manusia dari adanya bahaya-bahaya yang dapat memakan korban dengan menghubungkan bagian dari peralatan tersebut dengan sistem pentanahan. Prinsip Kerja dari sistem pentanahan adalah mengaliri arus induksi dan efek-efek lain yang timbul ke dalam tanah. [3]

Pentanahan adalah penghubung suatu titik rangkaian listrik dengan bumi dengan cara tertentu, apabila suatu tindakan pengamanan atau perlindungan yang akan dilaksanakan maka harus ada sistem pentanahan yang dirancang dengan benar. Agar sistem pentanahan dapat bekerja efektif, adapun sistem pentanahan adalah sebagai berikut :

a. Membuat jalur impedansi rendah ke tanah untuk pengamanan personil dan peralatan menggunakan rangkaian efektif.

b. Dapat melawan dan menyebarkan gangguan berulang dan arus akibat surja hubungan (surgecurrents).

c. Menggunakan bahan korosi terhadap bagian kondisi kimiawi tanah untuk meyakinkan kontinuitas sepanjang umur peralatan yang dilindungi.

d. Menggunakan sistem mekanik yang kuat namun mudah dalam pemeliharaan.

\subsection{Tahanan Jenis Tanah dan Tipe Tanah}

Harga tahanan jenis tanah harus diambil untuk keadaan yang paling buruk yaitu sewaktu tanah dalam keadaan kering dan dingin. Untuk melihat gambaran mengenai besarnya tahanan jenis tanah untuk bermacam-macam jenis tanah dapat dilihat pada tabel dibawah ini.

Tabel. 2.1 Tahanan Jenis Tanah [4]

\begin{tabular}{c|l|c}
\hline No & \multicolumn{1}{|c|}{ Jenis Tanah } & $\begin{array}{c}\text { Tahanan Jenis Tanah } \\
\text { (ohm-m) }\end{array}$ \\
\hline 1 & Tanah rawa & 30 \\
\hline 2 & Tanah liat dan tanah lading & 100 \\
\hline 3 & Pasir Basah & 200 \\
\hline
\end{tabular}




\begin{tabular}{c|l|c}
\hline 4 & Kerikil Basah & 500 \\
\hline 5 & Pasir dan kerikil kering & 1000 \\
\hline 6 & Tanah berbatu & 3000 \\
\hline
\end{tabular}

Dalam penggunaan data-data diatas sering terjadi kesulitan karena komposisi tanah biasanya terdiri dari dua atau lebih kombinasi lapisan dari bermacam-macam tanah. Hal yang penting dalam penyelidikkan karakteristik tanah ialah mencari tahanan jenis tanah. Harga tahanan jenis tanah ini selalu bervariasi sesua dengan keadaan tanah pada saat pengukuran, karena itu sebaiknya dicantumkan keadaan cuaca dan basah keringnya tanah pada waktu pengukuran dilakukan.

\subsection{Resistansi Pembumian [4]}

a. Resistansi pembumian dari elektrode bumi tergantung pada jenis dan keadaan tanah serta pada ukuran dan susunan elektrode.

b. Resitansi pembumian suatu elektrode harus dapat diukur. Untuk keperluan tersebut penghantar yang menghubungan setiap elektrode bumi atau susunan elektrode bumi harus dilengkapi dengan hubungan yang dapat dilepaskan.

c. Tabel 2.2 menunjukan nilai rata-rata resistansi elektrode bumi untuk ukuran minimum elektrode bumi.

Tabel 2.2 Resistansi Pembumian pada resistansi jenis $\rho 1=100 \Omega$-meter

\begin{tabular}{|c|c|c|c|c|c|c|c|c|c|c|}
\hline 1 & 2 & 3 & 4 & 5 & 6 & 7 & 8 & 9 & 10 & 11 \\
\hline $\begin{array}{l}\text { Jenis } \\
\text { Elektrode }\end{array}$ & \multicolumn{4}{|c|}{ Pita atau penghantar pilin } & \multicolumn{4}{|c|}{ Batang atau pipa } & \multicolumn{2}{|c|}{$\begin{array}{l}\text { Pelat vertikal } \\
\text { dengan sisi } \\
\text { atas } \\
- \\
\pm 1 \text { m dibawah } \\
\text { permukaan } \\
\text { tanah }\end{array}$} \\
\hline & \multicolumn{4}{|c|}{ Panjang (m) } & \multicolumn{4}{|c|}{ Panjang (m) } & \multicolumn{2}{|c|}{ Ukuran $\left(\mathrm{m}^{2}\right)$} \\
\hline & 10 & 25 & 50 & 100 & 1 & 2 & 3 & 4 & 5 & 6 \\
\hline $\begin{array}{l}\text { Resistansi } \\
\text { pembumi } \\
\text { an }(\Omega)\end{array}$ & 20 & 10 & 5 & 3 & 70 & 40 & 30 & 20 & 35 & 25 \\
\hline
\end{tabular}

Karena tahanan tanah berkaitan langsung dengan air dan suhu, maka dapat saja diasumsikan bahwa tahanan pentanahan suatu sistem akan berubah sesuai perubahan iklim setiap tahunnya. Variasi-variasi tersebut dapat dilihat karena kandungan air dan suhu lebih stabil pada kedalaman yang lebih besar, maka agar dapat bekerja efektif sepanjang waktu, 
sistem pentanahan dapat dikonstruksikan dengan elektrode atau pasak tanah yang ditancapkan cukup dalam dibawah permukaan tanah. Hasil terbaik akan diperoleh apabila kedalaman elektrode atau pasak mencapai tingkat kandungan air yang tetap. [5]

\subsection{Pengaruh Kelembaban}

Harga tahanan jenis tanah sangat dipengaruhi oleh konsentrasi air tanah. Pada kelembaban tanah yang rendah tahanan jenis tanah besar, sebaliknya semakin besar konsentrasi air dalam tanah, maka harga tahanan jenis akan semakin kecil. Proses mengalirnya arus listrik didalam tanah sebagai besar adalah karena proses elektrolisasi, maka dari itu didalam air tanah akan mempengaruhi konduktivitas atau daya hantar listrik tanah tersebut. Dengan demikian tahanan jenis tanah akan dipengaruhi pula oleh besaran konsentrasi air tanah. Semakin besar kosentrasi air di dalam tanah maka konduktivitas tanah akan semakin besar, sehingga tahanan jenis tanah akan turun sesuai dengan hubungan pada gambar 2.1 dibawah ini. [6]

Tanah yang kering atau tanah dengan konsentrasi air dalam tanahnya rendah sekali (dibawah 10 mempunyai tahanan jenis yang besar sekali atau dengan kata lain merupakan isolator yang baik. Tetapi dengan kenaikan konsentrasi air sampai $15 \%$, tahanan jenis tanah akan menurun dengan cepat sekali.

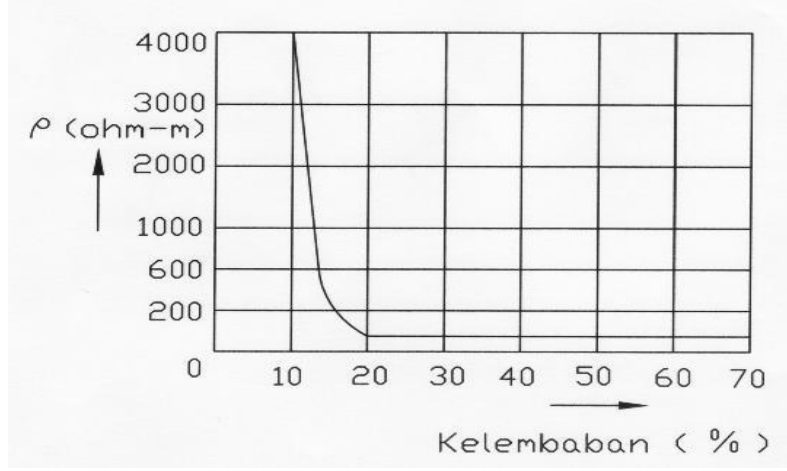

Gambar.1 Perubahan Tahanan Jenis Tanah Terhadap Kelembaban

Satu hal yang menarik dari gambar 2.1 adalah bahwa harga tahanan jenis tahanan tanah menunjukan adanya kejenuhan untuk kelembaban harga tahanan diatas $15 \%$, maka kenaikan didasari kelembaban tidak banyak terhadap tahanan jenis tanah. Oleh karena itu, penting bagi kita untuk menambakan elektrode pentanahan pada tempat yang berhubungan langsung dengan air tanah. Untuk melakukan hal ini elektrode-elektrode pentanahan ditanam di tempat-tempat yang cukup dalam di bawah permukaan air.

Dengan jalan demikian pula, maka pengaruh perubahan musim terhadap tahanan jenis tanah atau terhadap tahanan pentanahan elektrode dapat diperkecil.

Cara lain untuk memperkecil tahanan jenis tanah serta pengaruh dari musim adalah dengan jalan memberikan semacam zat kimia disekitar elektroda secara periodic yang terlihat pada gambar 


\section{2 dibawah ini.}

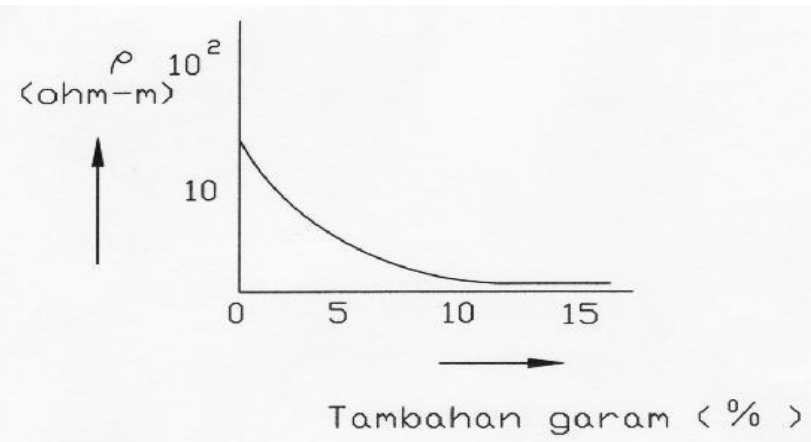

Gambar 2. Penggaramaan Tanah

Zat kimia tersebut akan memperkecil tahanan jenis tanah disekitar elektrode pentanahan, sehingga tahanan pentanahan serta perubahannya karena musim akan menjadi kecil. [4]

\subsection{Pengaruh Suhu dan Temperatur}

Temperatur tanah disekitar elektrode pentanahan juga berpengaruh terhadap besaran tahanan jenis tanah terutama bila temperatur dibawah titik beku.

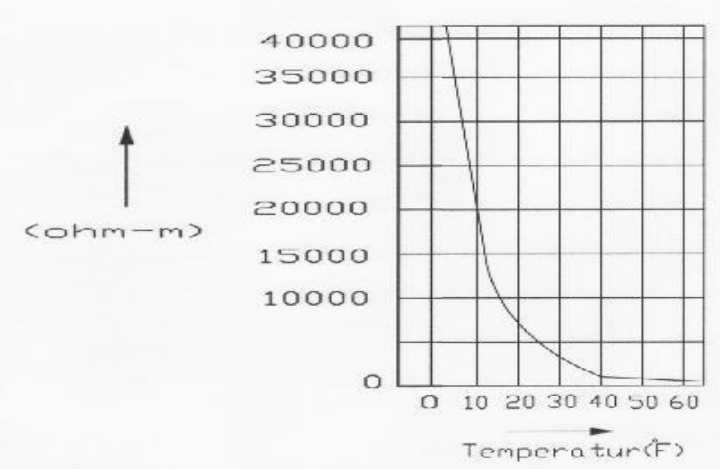

Gambar 3. Pengaruh temperatur terhadap tahanan jenis tanah.

Dibawah harga titik beku, perubahan temperatur yang sedikit saja akan menyebabkan harga tahanan jenis tanah tersebut dengan cepat mengalami kenaikan. Pada temperatur dibawah titik beku, air didalam tanah akan membeku, molekul-melekul air dalam tanah akan sulit untuk bergerak sehingga daya hantar listrik tanah menjadi rendah sekali. [4].

\subsection{Menghitung Tahanan Pentanahan}

Besar tahanan dari berbagai pentanahan tanah dapat dihitung dengan menggunakan persamaan dibawah ini.

1. Pentanahan rod (elektrode batang) 
Dibawah ini diperlihatkan distribusi tengangan yang terjadi untuk satu batang elektrode dan dua batang elektrode yang ditanam tegak lurus ke dalam tanah, di mana arus mengalir dari elektrode tersebut ke tanah sekitarnya.

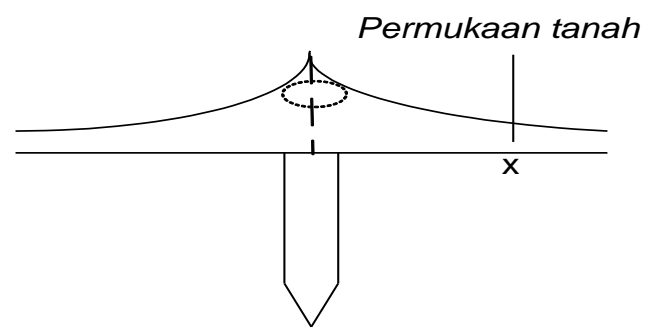

Gambar 4. Distribusi tegangan sekitar satu batang elektrode

Dimana :

Ux : tegangan elektrode pentanahan atau tengangan udara elektrode dengan tanah

X : jarak dari eketrode

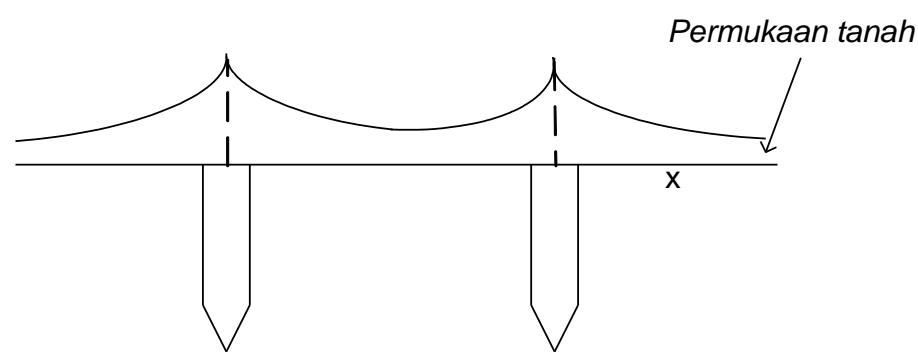

Gambar 5 Distribusi tegangan sekitar dua batang elektrode

dengan dimikian, semakin banyak jumlah elektrode yang ditanam tegak lurus ke dalam tanah maka tahanan pentanahan semakin kecil dan distribusi tegangan akan semakin merata.

2. Satu batang elektrode yang ditaman tyegak lurus kedalam tanah

Dari suatu konduktor terdapat hubugan antara tahanan dan kapasitansi sebesar :

$\mathrm{R}=\rho / 2 \pi \mathrm{C}$

Dimana :

$\mathrm{R}$ : tahanan $(\mathrm{Ohm})$

$\mathrm{P} \quad$ : tanahan jenis tanah tiap lapisan (Ohm-m)

C : kapasitansi (farad)

Kapasitansi ini termasuk kapasitansi dari bayangan konduktor yang ditanam kedalam tanah. Pada gambar 2.6 tampak satu batang elektrode berbentuk silinder berdiameter $2 a$ 
dengan pajang L yang ditanam tegak lurus permukaan tanah, dengan bayangan di atas permukaan tanah. Untuk menghitung kapasitansi elektrode pentanahan dan bayangan digunakan metode potensial rata-rata menurut G.W.O. Home. Dalam persoalan pentanahan, elektrode pentanahan merupakan bahan penghantar yang membawa yang terdistribusi (menyebar) di sekeliling elektrode. Dengan cara seperti ini potensial di setiap tempat pada permukaan elektrode akan sama. Bila pada elektrode tersebut diberikan suatu muatan yang merata maka kapasitansi dapat dihitung dengan metode potensial rata-rata. Hasil yang didapatkan untuk suatu batang elektrode berbentuk selinder yang ditanam seluruhnya di dalam tanah dinyatakan dengan persamaan (2):

$$
\frac{1}{C}=\frac{1}{L}\left(\operatorname{Ln} \frac{4 L}{a}-1\right)
$$

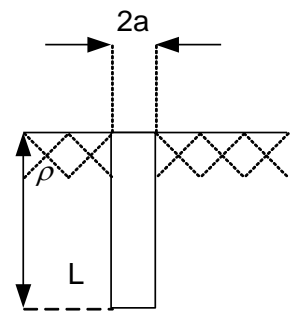

(a)

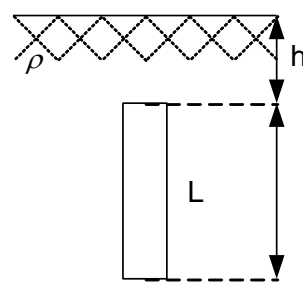

(b)

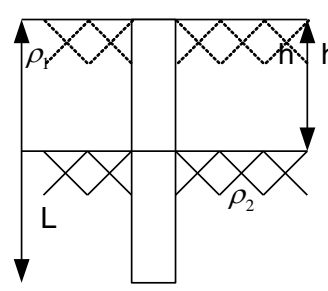

(c)

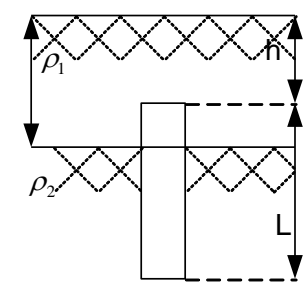

(d)

Gambar 6 satu batang elektrode tegak lurus ke dalam tanah

Oleh sebab itu tanahan dari satu batang elektrode yang ditanam tegak lurus permukaan tanah, menurut H.B. Dwight, didapat dengan mensubtitusikan persamaan (2) kedalam persamaan (1) sehingga diperoleh persamaan untuk gambar (3) sebagai berikut:

$$
R_{n}=\frac{\rho}{2 \pi L}\left[\operatorname{Ln} \frac{4 L}{a}-1\right]
$$

Untuk elektrode batang yang di tanam tegak lurus dan pada kedalaman beberapa $\mathrm{cm}$ di bawah permukaan tanah (Gambar 6)

$R_{d 1}=\frac{\rho}{2 \pi L}\left[\operatorname{Ln}\left(\frac{2 L}{a}\right)-1\right]$

Untuk gambar 6.c , satu batang elektrode tegak lurus kedalam tanah dan menembus lapisan kedua tanah tersebut. Dalam hal ini berlaku persamaan: 


$$
R_{d 1}=R_{a}=\frac{\rho_{2}}{2 \pi L}\left[\operatorname{Ln}\left(\frac{2 L}{a}\right)-1\right]
$$

Untuk gambar 6.d, satu batang elektrode tegak lurus kedalam tanah pada kedalaman beberapa $\mathrm{cm}$ di bawah permukaan tanah dan menembus lapisan kedua tanah tersebut. Dalam hal ini berlaku persamaan:

$$
\begin{aligned}
& R_{d 1}=R_{b}=\frac{\rho_{1}}{2 \pi\left(h-h_{b}\right)}\left[\operatorname{Ln}\left(\frac{2 L}{a}\right)-1+\frac{L n 2}{1+\frac{(4 L n 2) R_{b}}{L}}\right]+\frac{\rho_{1}}{h} \emptyset_{0} \ldots \\
& \emptyset_{0}=\frac{\frac{1}{2 \pi}\left(\operatorname{Ln} \frac{1}{1-K}\right)}{\sqrt{\left(\frac{N}{F_{0}}-1\right)^{2}}+1} \\
& F_{0}=\frac{L}{1-0.9 K}
\end{aligned}
$$

Di mana :

Rd1 : Tahanan untuk satu batang elektrode yang ditanam tegak lurus

$$
\text { permukaan tanah (Ohm) }
$$

L : Panjang elektrode batang (meter)

a : Jari-jari batang elektrode $(\mathrm{cm})$

$\rho \quad$ : Tahanan jenis tanah rata-rata (Ohm-m)

(indeks 1 atau 2 menunjukan lapisan tanah)

$h b$ : Kedalaman penanaman elektrode (meter)

\subsection{Pengukuran Tahanan Pentanahan}

Alat yang digunakan adalah Earth Tester, yang didesain dan dikeluarkan menurut safety standart oleh IEC-1010 (EN 61010). Alat ini untuk mengukur tanahan elektrode pentanahan. Ada berbagai macam instrument pengukur tanahan pentanahan. Pada instrument cara pengukuran ada 2 macam yaitu Pengukuran normal (metoda 3 kutub) dan Pengukuran praktis (metoda 2 kutub)

\section{METODE PENELITIAN}

Penelitian dilakukan dengan metode eksprimental dengan langkah-langkah penelitian ;

1. Surve lokasi penelitian, Penelitian dan pengukuran di lokasi panel distribusi gedung rekam medis Rumah Sakit Dr. Mohammad Hoesin - Palembang.

2. Persiapan peralatan dan Alat Ukur, Tools set dipersiapkan untuk persiapan pengukuran dan untuk alat Ukur digunakan Digital Earth Tester (Kyoritsu 4105A) 
3. Penentuan Titik sentris tempat atal ukut elektrode Earth Tester dipasang ditanam. Metode pengukuran tahanan menggunakan metode tiga titik, dimana 1 batang elektrode memiliki 2 buah titik atau elektrode pasak bantu.

\section{PEMBAHASAN}

\subsection{Perhitungan Tahanan Pentanahan}

Perhitungan tahanan pentanahan untuk kedalaman elektrode dapat menggunakan persamaan:

$$
\begin{aligned}
& R=\frac{1000}{2 \times 3,14 \times 2000} \times\left(\ln \frac{4 \times 2000}{0,6}-1\right) \\
& R=0,67 \Omega
\end{aligned}
$$

Berdasarkan perhitungan diatas pada intalasi rekam medis RSUP Dr. Mohammad Hoesin Palembang mendapatkan tahanan resistansi pentanahan dibawah $5 \Omega$, kedalaman penanaman elektrode 20 meter.

Berdasarkan pengukuran yang dilakukan salama 15 hari di Panel Distribusi Gedung instalasi rekam medis hasil yang didapatkan :

Tabel 4.1 Pengukuran Resistansi Pentanahan Dari Pukul 7.30 sampai 09.30 WIB

\begin{tabular}{c|l|l|l|c}
\hline No & \multicolumn{1}{|c|}{ Tanggal } & \multicolumn{1}{c|}{ Hari } & \multicolumn{1}{c}{ Cuaca } & Resistansi \\
\hline 1 & $15 / 04 / 2017$ & jum'at & cerah & 0,15 \\
\hline 2 & $16 / 04 / 2017$ & Sabtu & cerah & 0,08 \\
\hline 3 & $17 / 04 / 2017$ & minggu & cerah & 0,08 \\
\hline 4 & $18 / 04 / 2017$ & Senin & cerah & 0,13 \\
\hline 5 & $19 / 04 / 2017$ & Selasa & cerah & 0,14 \\
\hline 6 & $20 / 04 / 2017$ & Rabu & cerah & 0,13 \\
\hline 7 & $21 / 04 / 2017$ & Kamis & gerimis & 0,06 \\
\hline 8 & $22 / 04 / 2017$ & jum'at & cerah & 0,14 \\
\hline 9 & $23 / 04 / 2017$ & Sabtu & berawan & 0,07 \\
\hline 10 & $24 / 04 / 2017$ & minggu & gerimis & 0,05 \\
\hline 11 & $25 / 04 / 2017$ & Senin & hujan & 0,09 \\
\hline 12 & $26 / 04 / 2017$ & Selasa & berawan & 0,16 \\
\hline 13 & $27 / 04 / 2017$ & Rabu & berawan & 0,15 \\
\hline 14 & $28 / 04 / 2017$ & Kamis & cerah & 0,15 \\
\hline 15 & $29 / 04 / 2017$ & jum'at & cerah & 0,16 \\
\hline
\end{tabular}

Dari tabel hasil pengukuran di atas didapatkan tahanan resistansi terbesar $0.16 \Omega$ pada hari selasa 26 April 2017 pada saat kondisi cuaca berawan dengan banyaknya penggunaan peralatan listrik dan jum'at 29 April 2017 pada saat kondisi cuaca cerah dengan banyaknya penggunaan peralatan listrik, selanjutnya tahanan resistansi terkecil $0.5 \Omega$ pada hari minggu 24 April 2017 pada saat kondisi cuaca gerimis dengan tidak semua peralatan listrik digunakan. 


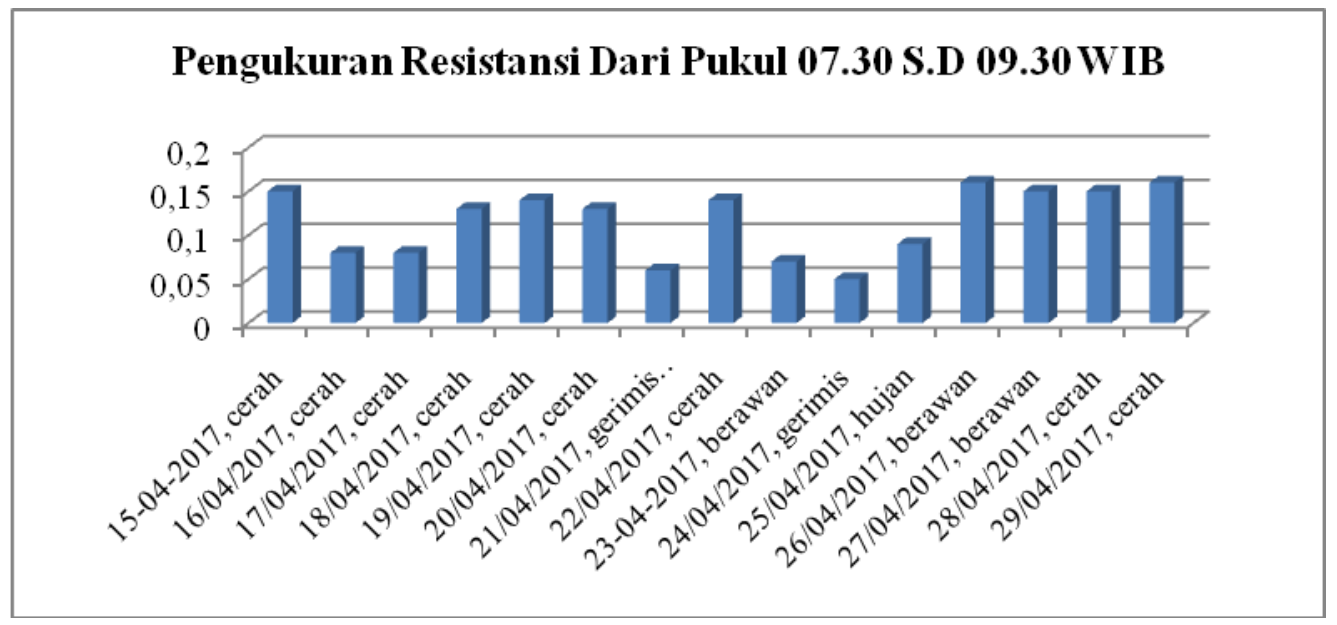

Gambar 7 Grafik Hasil Pungukuran Resistansi Pentanahan Pada Sore Hari

Dari Tabel hasil pengukuran di atas didapatkan tahanan resistansi terbesar $0.09 \Omega$ pada hari senin 18 April 2017 pada saat kondisi cuaca berawan dengan banyaknya penggunaan peralatan listrik dan rabu 27 April 2017 pada saat kondisi cuaca cerah dengan banyaknya penggunaan peralatan listrik dan tahana resistansi terkecil $0.04 \Omega$ pada hari/tanggal sabtu 23 April 2017 pada saat kondisi cuaca hujan dengan tidak semua peralatan listrik digunakan.

Tabel 4.2 Pengukuran Resistansi Pentanahan Dari Pukul 15.00 s.d 17.00 WIB

\begin{tabular}{c|l|l|l|c}
\hline No & \multicolumn{1}{|c|}{ Tanggal } & \multicolumn{1}{c|}{ Hari } & \multicolumn{1}{c}{ Cuaca } & Resistansi \\
\hline 1 & $15 / 04 / 2017$ & jum'at & Berawan & 0,08 \\
\hline 2 & $16 / 04 / 2017$ & Sabtu & Cerah & 0,07 \\
\hline 3 & $17 / 04 / 2017$ & minggu & Cerah & 0,06 \\
\hline 4 & $18 / 04 / 2017$ & Senin & Berawan & 0,09 \\
\hline 5 & $19 / 04 / 2017$ & Selasa & Cerah & 0,08 \\
\hline 6 & $20 / 04 / 2017$ & Rabu & Berawan & 0,07 \\
\hline 7 & $21 / 04 / 2017$ & Kamis & Berawan (Libur) & 0,07 \\
\hline 8 & $22 / 04 / 2017$ & jum'at & Berawan & 0,08 \\
\hline 9 & $23 / 04 / 2017$ & Sabtu & Hujan & 0,04 \\
\hline 10 & $24 / 04 / 2017$ & minggu & Cerah & 0,07 \\
\hline 11 & $25 / 04 / 2017$ & Senin & Gerimis & 0,07 \\
\hline 12 & $26 / 04 / 2017$ & Selasa & Gerimis & 0,06 \\
\hline 13 & $27 / 04 / 2017$ & Rabu & Cerah & 0,09 \\
\hline 14 & $28 / 04 / 2017$ & Kamis & Gerimis & 0,08 \\
\hline 15 & $29 / 04 / 2017$ & jum'at & Hujan & 0,06 \\
\hline
\end{tabular}

Dari tabel hasil pengukuran di atas didapatkan tahanan resistansi terbesar $0.09 \Omega$ pada hari senin 18 April 2017 pada saat kondisi cuaca berawan dengan banyaknya penggunaan peralatan listrik dan rabu 27 April 2017 pada saat kondisi cuaca cerah dengan banyaknya penggunaan peralatan listrik dan tahana resistansi terkecil $0.04 \Omega$ pada hari sabtu 23 April 2017 pada saat kondisi cuaca hujan dengan tidak semua peralatan listrik digunakan. 


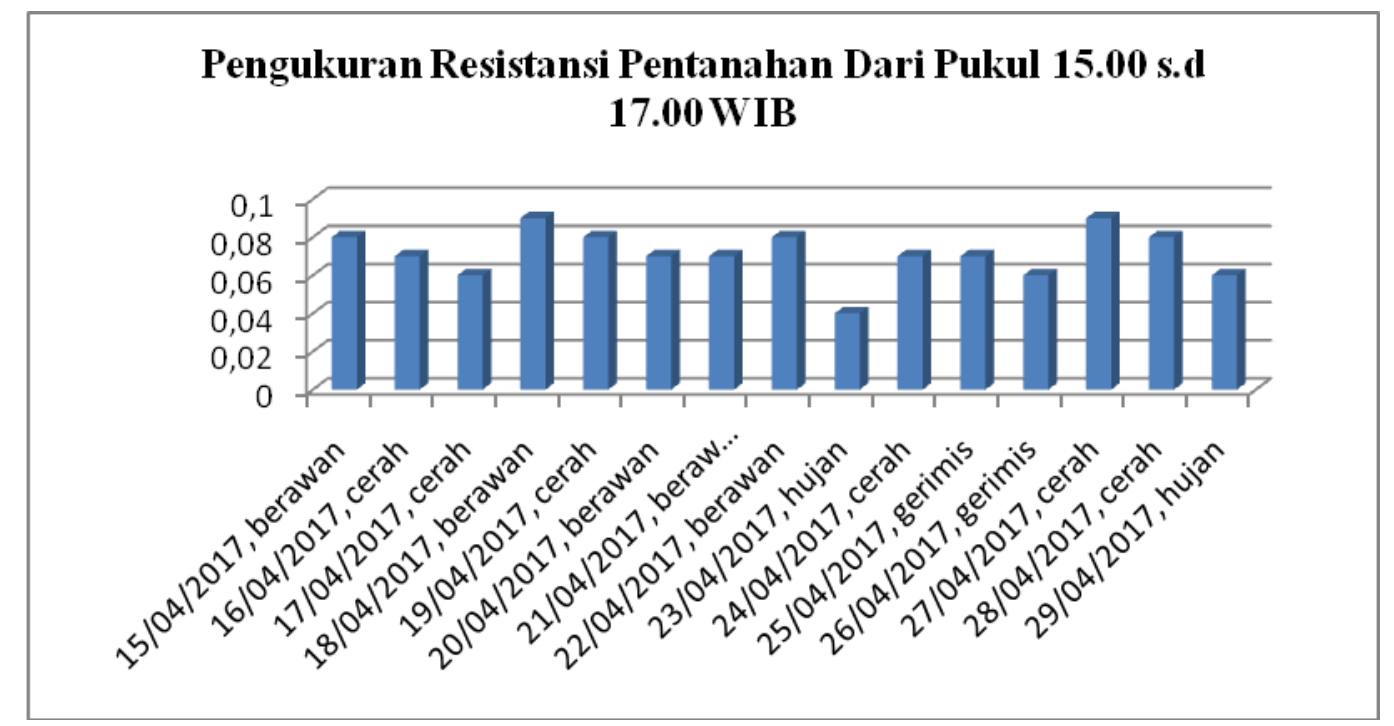

Gambar 4.2 Grafik Hasil Pungukuran Resistansi Pentanahan Pada Sore Hari

Dari Grafik hasil pengukuran di atas didapatkan tahanan resistansi terbesar $0.09 \Omega$ pada hari senin 18 April 2017 pada saat kondisi cuaca berawan dengan banyaknya penggunaan peralatan listrik dan rabu 27 April 2017 pada saat kondisi cuaca cerah dengan banyaknya penggunaan peralatan listrik dan tahana resistansi terkecil $0.04 \Omega$ pada hari sabtu 23 April 2017 pada saat kondisi cuaca hujan dengan tidak semua peralatan listrik digunakan.

Tabel. 4.3 Hasil Perbandingan antara perhitungan dan pengukuran

\begin{tabular}{c|c|c|c}
\hline \multirow{2}{*}{ No } & \multirow{2}{*}{ Perhitungan } & \multicolumn{2}{|c}{ Pengukuran } \\
\cline { 3 - 4 } & & $\mathbf{0 7 . 3 0}$ sd 09.00 WIB & $\mathbf{1 5 . 0 0}$ sd 17.00 WIB \\
\hline 1 & $\mathrm{R}=0.67 \Omega$ & $\mathrm{R}=0.11 \Omega$ & $\mathrm{R}=0.07 \Omega$ \\
\hline
\end{tabular}

Dari tabel hasil perbandingan di atas didapatkan tahanan resistansi dengan perhitungan $0.67 \Omega$ dengan rata-rata pengukuran mendapatkan hasil pada pagi hari $0.11 \Omega$ dan sore hari

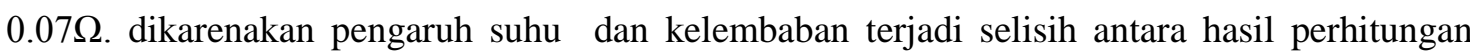
dengan pengukuran.

\section{KESIMPULAN}

Setelah melakukan perhitangan dan pengukuran, dapat diambil kesimpulan sebagai berikut :

1. Berdasarkan perhitungan resistansi tahanan pentanahan instalasi rekam medis RSUP Dr. Mohammad Hoesin Palembang berada dibawah 0,67 $\Omega$.

2. Berdasarkan pengukuran resistansi tahanan pentanahan pada waktu pagi hari di Panel Distribusi Gedung instalasi rekam medis RSUP Dr. Mohammad Hoesin Palembang didapatkan niala tahanan resistansi dengan rata-rata $0.11 \Omega$. 
3. Berdasarkan pengukuran resistansi tahanan pentanahan pada waktu sore hari di Panel Distribusi Gedung instalasi rekam medis RSUP Dr. Mohammad Hoesin Palembang didapatkan nilai tahanan resistansi dengan rata-rata $0.07 \Omega$.

\section{DAFTAR PUSTAKA}

[1] Harnoko Stephanus "Pengaruh panjang Elektrode sangkar Delta pada Nilai Resistans Pentanahan di Lokasi Sempit”.,. Jurnal Teknik Elektro dan Teknologi Informasi, Fakultas Teknik UGM, Yogyakarta.2016

[2] Ir. H. Hazairin samaulah, M.Eng.,Ph.D. "Dasar-dasar sistem proteksi tenaga listrik", Universitas Sriwijaya, Palembang. 2004.

[3] Ir. Sunarno, M.Eng., Ph.D "Mekanikal Elektrikal Lanjutan”,. Penerbit Andi. Yogyakarta. 2006

[4] Persyaratan Umum Instalasi Listrik 2000 (PUIL 2000), Yayasan PUIL, Jakarta 2000.

[5] TS Hutauhuruk "Pengetanahan Netral Sistem Tenaga dan Pengetanahan Peralatan". Penerbit Erlangga Jakarta.1991

[6] AS Pabla dan Abdul Hadi. "Sistem Distribusi Daya Listrik". Erlangga Jakarta.1991 